\title{
The Shift of Traditional Agroecosystems in the in Eastern Arc Catchments of Tanzania
}

\author{
Agnes G. Kapinga1* , Abimbola Sangodoyin², Olayinka 0. Ogunkoya ${ }^{3}$, Marco B. Sulley, \\ Franco J. Mbegallo5, Gordon T. Madamombe 6 \\ ${ }^{1}$ Department of Environmental Management, Pan Africa University Life and Earth Sciences Institute (PAULESI), \\ University of Ibadan, Ibadan, Nigeria \\ ${ }^{2}$ Department of Agriculture and Environmental Engineering, University of Ibadan, Ibadan, Nigeria \\ ${ }^{3}$ Department of Department of Geography, Obafemi Awolowo University, Ile-Ife, Nigeria \\ ${ }^{4}$ Pan Africa University Life and Earth Sciences Institute (PAULESI), University of Ibadan, Ibadan, Nigeria \\ ${ }^{5}$ Department of Agricultural Economics and Business, University of Dar es Salaam, Dar es Salaam, Tanzania \\ ${ }^{6}$ Environmental Management, Renewable Energy and Climate Change Research Centre, Harare Institute of Technology, \\ Harare, Zimbabwe \\ Email: *agnesg isbertkapinga @gmail.com, bimbo_sangodoyin@yahoo.co.uk, olayinkaogunkoya@gmail.com, \\ sulleymarco@gmail.com, mbegallofranco@gmail.com,gtmada@gmail.com
}

How to cite this paper: Kapinga, A.G., Sangodoyin, A., Ogunkoya, O.O., Sulley, M.B., Mbegallo, F.J. and Madamombe, G.T. (2019) The Shift of Traditional Agroecosystems in the in Eastern Arc Catchments of Tanzania. Agricultural Sciences, 10, 1343-1358. https://doi.org/10.4236/as.2019.1010098

Received: June 6, 2019

Accepted: October 22, 2019

Published: October 25, 2019

Copyright $\odot 2019$ by author(s) and Scientific Research Publishing Inc. This work is licensed under the Creative Commons Attribution International License (CC BY 4.0)

http://creativecommons.org/licenses/by/4.0/

\begin{abstract}
The purpose of this study was to identify the drivers of the shift of traditional agro-ecosystems and their implication on catchment resources management of Eastern Arc Catchments of Tanzania. Lower Mngeta and Upper Zigi water catchments are situated within Eastern Arc Mountains of Tanzania. Household questionnaire, key informant interviews and focus group discussion were used for collecting primary data. The findings indicated that most of the participants (85.9\% and 90.4\% in Lower Mngeta and Upper Zigi catchments respectively) depend on subsistence rain-fed agriculture for their livelihoods. However, there are significant changes in production as a result of land fertility deteriorating and negative climatic changes (seasonal shift). This has become a major challenge for most of the farmers. To cope with agro-ecosystem dynamics, farmers in the study areas use both traditional and modern strategies as illustrated in the results section. While tradition always reported to be inexpensive, some modern agro-ecosystem practices reported to cause siltation, killing of fish and herbal plants, easy rotting of seeds (for maize) and bad aroma (for rice)in spite of having a high rate of return. It was also reported that depletion of traditions and norms of conduct, accelerated by multi-cultural interaction from immigrants, have led to deterioration of traditional agriculture practices. Moreover, arrival of agriculture companies and introduction of spice farming was reported to have caused manpower imbalance, unequal distribution of natural resources and less diversity of indige-
\end{abstract}


nous plants. The study concludes that communities are much into economic opportunity derived from agro-ecosystem than stewarding it. The study recommends that the effort restoring catchment ecosystem should come from both traditional and modern strategies so as to harmonize and accommodate environmental, economic and traditional values.

\section{Keywords}

Agro-Ecosystem, Culture and Diversity

\section{Introduction}

Agro-ecosystems have been significantly modified by humans to produce food, fibre, fuel, and other agriculture products [1]. They are specialized, controlled ecosystems designed for the production of agricultural products and are characterized by three dimensions: biophysical, socioeconomic and human community [2]. The deterioration of agro-ecosystems has led to crop failure culminating in the recurring food insecurity experiences across the globe [3]. Climate Change is set to exacerbate food scarcity. Undernourishment is an inevitable consequence of food scarcity which the world is set to experience, if the deterioration of agro-ecosystems remains unabated. In 2018, FAO reported that the number of undernourished people had increased from 783.7 million in 2014 to 820.8 million in 2017 [4].

While there have been significant improvements in enhancing the agro-ecosystem function, people in developing countries are still failing to meet their food demand [4]. The use of improved agriculture chemicals, precision agriculture, irrigation and crop improvement technologies are some of the strategies to enhance food security but are detrimental to the environment in the long run. Excessive use of in-organic agrochemicals is leading to biodiversity loss, ozone depletion and global warming [5]; pesticides leads to biodiversity loss [6]; excessive irrigation causes salinization of soil which impacts on growth of plants and entire ecosystem; and also conflicts due to water resources allocation [7]. Modern agricultural intensification was reported to be incompatible with sustainable of agro-ecosystems through increase in incidences of pest, diseases, and weeds, deterioration of soil fertility, structure and inequality [8].

Like other sub-Saharan Africa, the main livelihood activity for rural communities in Tanzania is rain-fed agriculture which is not spared of crop failure as a result of changing agro-ecosystem dynamics. More than $70 \%$ of the Tanzanian residents are relying on traditional farming as the primary source of livelihoods [9]. The crop failure affects not only food security but also prompts over-extraction of environmental resources such as timber and non-timber forest products as a mechanism of coping with food insecurity and other need such as cash [9]. 
Several studies conducted in both developed and developing countries have been much on understanding impacts of changing agro-ecosystem on agriculture production [8] [10] [11] [12]. There is a dearth in literature on understanding the implication agro ecosystems dynamic to water catchments management, particularly in Tanzania. Therefore, this study focuses on understanding the phenomena that lead to traditional agro-ecosystem change in Lower Mngeta and Upper Zigi catchments of Eastern Arc Mountains, Tanzania.

\section{Materials and Methods}

\subsection{The Study Area}

The study was conducted in two catchments in rural Tanzania: Lower Mngeta catchment, located at the foot slope of Udzungwa Mountains, Kilombero District, in Tanzania's Morogoro Region, and Upper Zigi catchment, located at the upper slope of East Usambara Mountains, Muheza District in Tanzania's Tanga Region between January 2018 and May 2018. The Upper Zigi catchment is situated approximately between Latitude $4^{\circ} 48^{\prime}$ and $5^{\circ} 13^{\prime} \mathrm{S}$, Longitude $38^{\circ} 32^{\prime}$ and $38^{\circ} 48^{\prime} \mathrm{E}$ with a size of $2080.13 \mathrm{~km}^{2}$. Lower Mngeta catchment is situated approximately between Latitude $8^{\circ} 0^{\prime}$ and $6^{\circ} 77^{\prime} \mathrm{S}$, Longitude $37^{\circ} 45^{\prime}$ and $12^{\circ} 59^{\prime} \mathrm{E}$ with size of $515.22 \mathrm{~km}^{2}$ (see Figure 1 and Figure 2). The sampled villages were Mngeta, Mofu, and Mchombe for Lower Mngeta catchment, while, Sakale, Kisiwani, Bombani, and Nkumba were sampled for Upper Zigi catchment. The selection of the catchments was based on ability of the catchments to generate ecosystem services which support livelihood that support agriculture activities and also deterioration of catchment ecosystem [13]. The central livelihood activity is agriculture which employs more $90 \%$ of the population [14] [15]. According to the 2012 Tanzania Population Census, Muheza (Upper Zigi sub-catchment) and Kilombero (Lower Mngeta sub-catchment) districts populations were 204,461 and 407,880 respectively. The mean population density is about 77 persons per $\mathrm{km}^{2}$ and 31 persons per $\mathrm{km}^{2}$ for Muheza and Kilombero Districts respectively [16].

\subsection{Data Sources}

The primary data were collected using questionnaire surveys that were administered to households living in catchment areas. In addition to the questionnaire, focus group discussion, and key informant interview were used for qualitative data collection.

\subsection{Methods and Tools for Primarydata Collection}

\subsubsection{Key Informant Interview}

To identify key informants, snow bowling was used. Five (5) people who have lived in the catchment for more than 30 years were selected with the help of Village Government. 

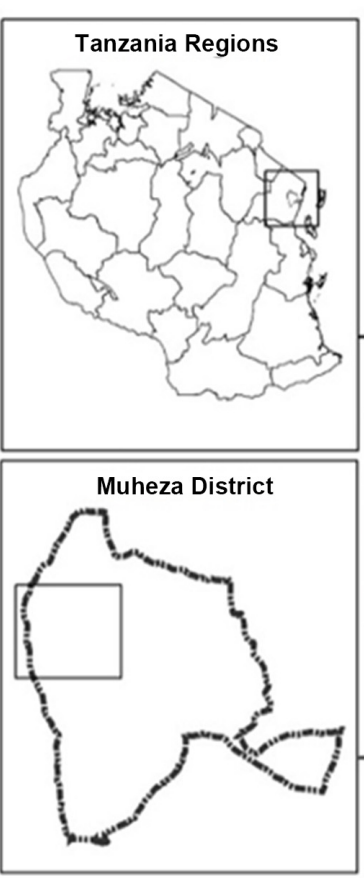

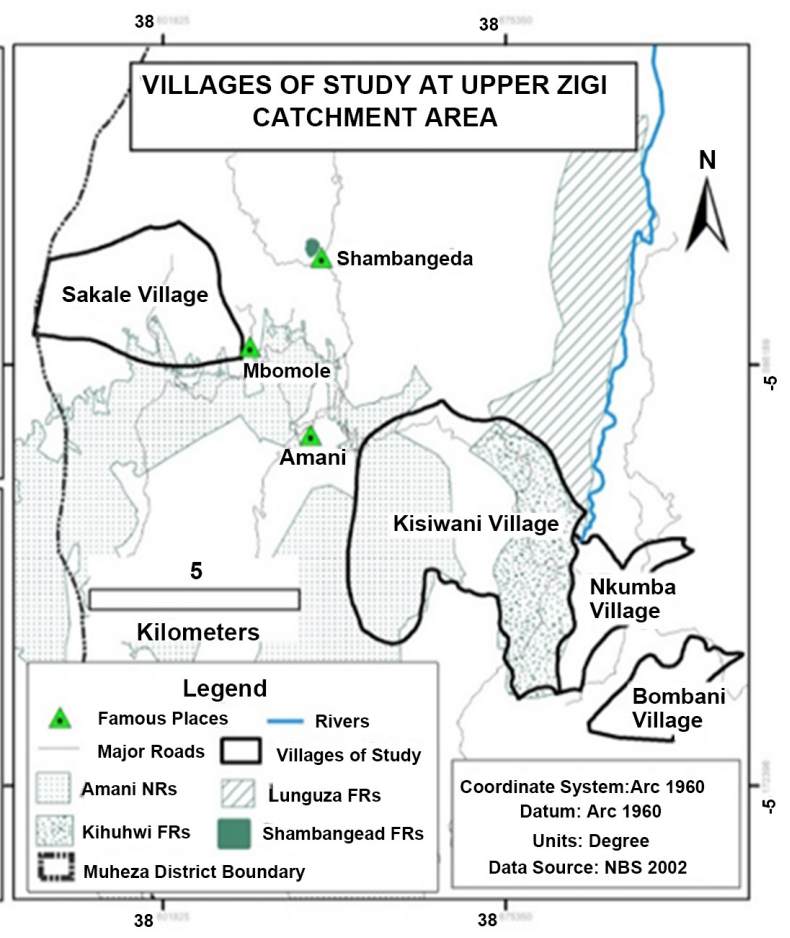

Figure 1. The upper Zigi Sub-catchment.
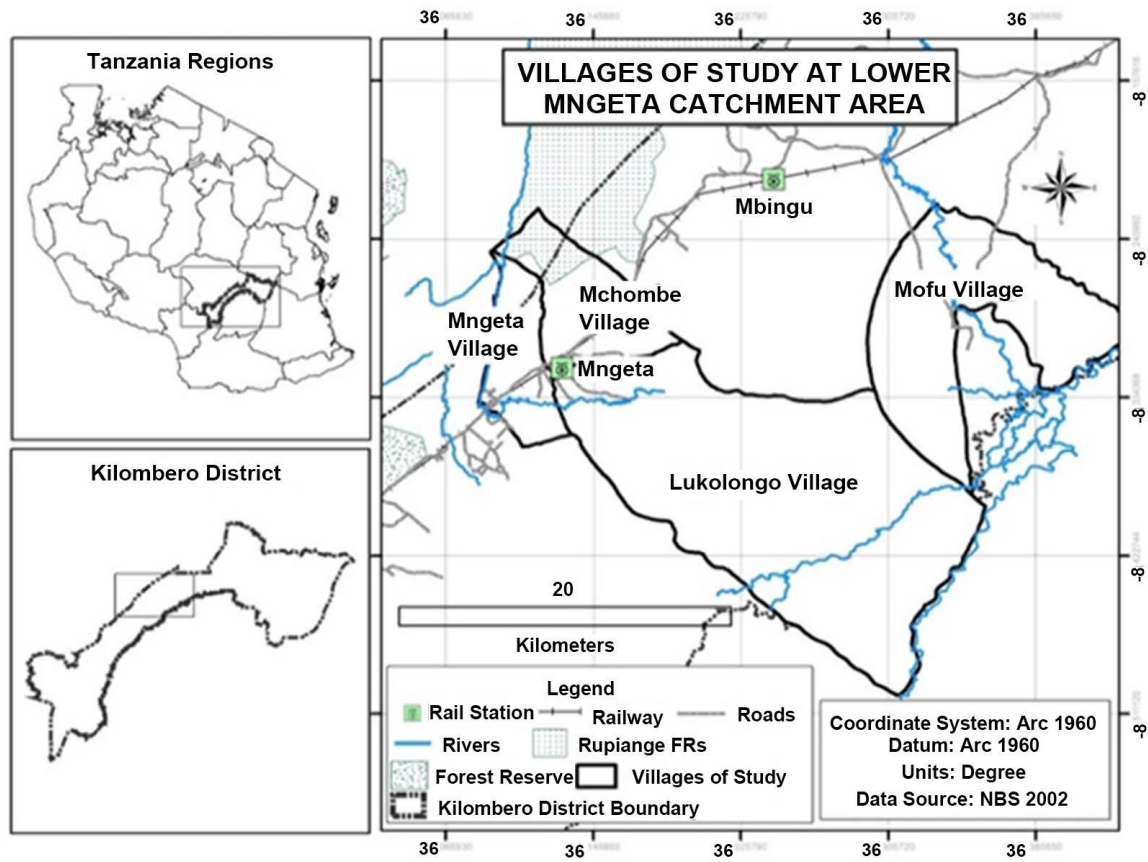

Figure 2. The lower Mngeta Sub-catchment.

\subsubsection{Focus Group Discussion}

Twenty (20) Focus Group Discussions (FGD) were conducted; 10 in each of the two catchment areas. For credibility and active participation, each group of between 10 - 15 participants comprised both men and women. A total of 147 and 158 participants for Lower Mngeta and Upper Zigi catchment respectively were 
selected. The data captured were about community experiences in agro-ecosystem shift.

\subsubsection{Household Questionnaire}

The questionnaire surveys were administered to head of household. The stratified methodology was deployed to calculate the sample size using Equation (1) [17]. $10 \%$ of confidence interval was used in this study as it gives a true representation of the population under study [18]. Table 1 shows the sample size used in questionnaire survey.

$$
n=\frac{N}{(1+N) * e^{2}}
$$

where,

$$
\begin{aligned}
& N=\text { size of a targeted population } \\
& n=\text { the sample size } \\
& e=\text { the confidence interval }
\end{aligned}
$$

\subsection{Data Analysis}

\section{Analysis of Primary Data}

Data collected using questionnaire were analysed using frequency statistics in term of percentages. The qualitative data collected using focus group discussion and key informant interview were analysed using content statistic to preserve the meanings of phenomena as intended by the local community under study. All information was meticulously processed and recorded. The next step was data reduction in which all information collected was assessed to ascertain it had meaningful content based on the research question. All meaningful, usable, and relevant information was transformed into a simplified format that can be understood. The processed information was then grouped into meaningful themes and patterns. The grouped themes and content pattern were then assembled, organized and displayed into textual formats.

Table 1. Number of human population, households and sampled households.

\begin{tabular}{ccccc}
\hline Sub-catchment & Village & Population & No. Household & Sample size \\
\hline Mngeta & 5811 & 999 & 100 \\
Lower Mngeta & Mofu & 2364 & 1021 & 134 \\
& Mchombe & 5421 & 1339 & 336 \\
\hline Total & 13596 & 3359 & 40 \\
& Sakale & 1138 & 400 & 32 \\
& Kisiwani & 1269 & 316 & 45 \\
& Bombani & 1021 & 448 & 25 \\
& Nkumba & 996 & 246 & 142 \\
\hline
\end{tabular}




\section{Results and Discussion}

\subsection{Traditional Agro-Ecosystem Practices}

\subsubsection{Labour Division}

Traditionally, Lower Mngeta communities, particularly Ndamba ethnic group, had societal labour division. Women were responsible for crop farming activities while men are required to undertake activities in fishing and hunting. From 1990s to date, men also engage themselves in crop farming activities due to imposed fishing restrictions, decline of fish stocks, and economic opportunities obtained from farming activities. The massive shift of men from fishing and hunting to farming activities led to the catchment disturbances such as deforestation and loss of endemic grass species due to ploughing of extensive land parcels. On the other hand, in Upper Zigi catchment, men are participating in all livelihood activities including agriculture except domestic activities such as cooking and hygiene, which are conducted by women. The results also explain that the agro-ecosystems of Eastern Arc Catchments is influenced by cultural history. In this case, understanding the cultural diversity across space is vital for managing agro-ecosystem. The result from this study is similar to [19] who reported that gender roles facilitate positive management of agro-ecosystems through their distinctive roles, responsibilities, and knowledge.

\subsubsection{Shifting Cultivation}

In both catchments, shifting cultivation was a means to deal with loss of land fertility, soil erosion, diseases, and weeds. Once the harvest declined and pest proliferated, farmers perceived that soil fertility had diminished, hence clearing forest for cultivation leaving the fields lying fallow. On average of every five (5) years, Lower Mngeta farmers reported to shifts to either virgin or fallowed land. For the Upper Zigi catchment, shifting cultivation was also conducted though there was no specific time to shift, farmers shifted once they felt the soil fertility had deteriorated. It was reported that land cultivated for long time had much more weeds compared to the new land cultivated for only a few years, hence weed proliferation was a key indicator of soil fertility. Key informants in Upper Zigi catchment were recorded saying, "Scarcity of land due to increase of population and laws with regards to deforestation, few households' practices shifting cultivation". In Lower Mngeta, shifting cultivation is practiced mores during the flood; some farmers migrate to high land areas where they can farm with fewer impacts from flooding. However, from 2000 to date shifting cultivation is strictly prohibited by village governments as it destroys the environment. Biomass loss as a result of shifting cultivation contributes to the anthropic green-house gas emissions cause increase of carbon dioxide concentration [20]. Findings confirm [21] who reported that shifting cultivation provides an essential contribution to the stability and sustainability of the farming system since it is resilient to exogenous disturbances by exhibits a non-negative trend in crop yield. 


\subsubsection{Farm Preparation and Planting System}

In Lower Mngeta sub-catchment farming preparations used to start beginning October to December every year. Nowadays the time for farm preparation in Lower Mngeta catchment has changed; no specific months for farms preparation, farmers relies on weather patterns not traditionally known dates. During the FGD it was participants reported that before 1990 the low lying areas were moist throughout the year; currently they dry towards the beginning of the rainy season, hence they cannot plant some off-season plants such as cassava, potatoes, yams, and maize. Like in a similar study [22], slashing and burning of bushes was a common method of farm preparation in Upper Zigi catchment to reduce pest, diseases and weed proliferation as they believed it purified the soil. Zero tillage was used as cultivating method for saving cost of labour and soil conservation.

\subsection{Current Status of Farming Activities}

Most of the people (85.9\% for Lower Mngeta and 90.4\% for upper Zigi catchment) depend on subsistence rain-fed agriculture as the primary source of livelihood. Principal crops produced in order of importance in Lower Mngeta are rice, maize, and bananas, while in Zigi Catchment are maize, cassava, black pepper, and banana. Other crops such as cloves, cardamoms, and cinnamon are found in Zigi Catchment only, while, crop such as sesame, finger millet, sorghum, and cocoa were recorded in Lower Mngeta Catchment only. Sorghum, apart from serving as staple, it has cultural importance as it is used in brewing opaque beer for traditional and spiritual ceremonies. The results from the study were in agreement with the findings of another study which reported that over $70 \%$ of Tanzanian population depends on subsistent rain-fed agriculture for their livelihood and also agriculture contributes up to $24 \%$ of the gross domestic product (GDP) [9]. However, Tanzanian's GDP from agriculture was reported to have declined by 6\% from 2006 to 2016 [9]. The implication is that agricultural production is declining indicating the shift of traditional agro-ecosystems. Figure 3 shows percentage of household experience in crop failure from year 1987 to 2017.

\subsection{Dynamics of Agro-Ecosystem and its Impacts}

\subsubsection{Advancement in Technology}

Advancement of technology is reported to have been changing agro-ecosystems. Previously, people in Lower Mngeta catchment were using hand hoes in rain-fed organic farming. Later after agro-pastoralists (particularly Sukuma ethnic group who started arriving in the valley since 1990s), the advent of commercial farming, in which the indigenous people copied on how to use animals and tractors for ploughing and harrowing. This made people cultivate large parcels of land within a short time. In addition, the use of inorganic fertilizer and pesticide reported to kill some of herbs which were used for medicinal plants. One key 


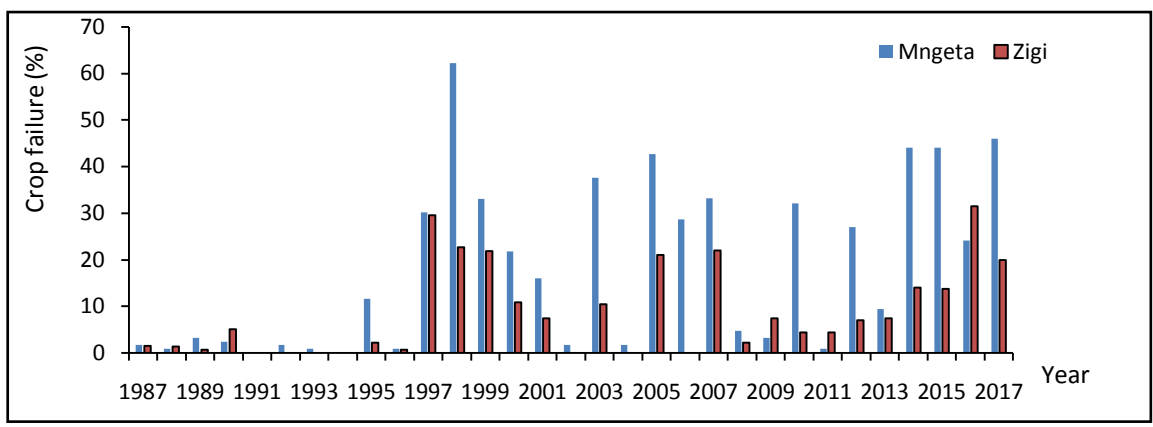

Figure 3. Households experience on crop failure.

informant in Lower Mngeta catchment was quoted saying, "back then the herbs for curing children and women diseases were found in farms around residents. Nowadays the herbs are hardly seen near residences because of application of herbicides". Furthermore, it was reported that previously no farming was conducted near the river banks due to strong beliefs and norms governing aquatic environment. Currently, due to environmental, socio-cultural, and economic changes, horticulture and rice production is conducted in both catchments using irrigation techniques. Spices farming is done in Upper Zigi catchment only. During key informant interviews in Upper Zigi catchment it was revealed that spice farmers since 2000's are gradually shifting to river banks due to drought. They said spice farming, particularly cloves, cardamom, and cinnamon performs better when there is high level of humidity. The introduction of exotic spices may lead to destruction of aquatic ecosystem equilibrium. This shift is driven by the intention to increase production accelerated by good available market [23]. The reasons to cultivate in river banks is due to several factors such as drought mitigation, fertile alluvial soils, closeness to water sources and local land pressure [24]. It was observed that stream bank cultivation had been established in Lower Mngeta catchment and the water bodies were said to be silted a result of this phenomena [23] [24].

\subsubsection{Plantation Agriculture}

Agricultural investors known as Kilombero Plantation Limited and East Usambara Tea Company (EUTCo) in Lower Mngeta and Upper Zigi respectively are highly dependent on catchment resources such as land, water and pleasant climate for the production. Communities in the study areas complained that government has preferential treatment in favour of investors at the expense local farmers even though both local farmers and the investors are using the same resources and sometimes the investors exploit more resources compared to the individual households. [25] Reported that the integration of biodiversity and human well-being is not yet to be achieved. The reason behind is that there is no equitable distribution of natural resources [26].

The presence of the agricultural company in Upper Zigi catchment was reported to be a factor responsible for crop failure. This is because the people with 
the energy to work, particularly the youths left their farms and went to work in tea plantation. One respondent was reported saying, "people are spending their life working in tea plantation (East Usambara Tea Company Ltd (EUTCO), after retirement, they just get back to the village life while they cannot even produce much". Although international investors help reduce unemployment in Africa [27], other important local economic activities like agriculture are negatively affected. It is because agricultural activities are highly dependent on youths to provide labour. Therefore, if the youths are not participating in agricultural activities, the production decreases leading to food shortage and poor economy of the country. This situation is similar to the observation [28] that foreign investors in developing countries may take away the skilled labour, which may prevent the technological advancement which also can reduce productivity.

\subsubsection{Climate Change Perceptions}

Unclear onset and ending of rain seasons, variability and unequal distribution of rainfall patterns were reported in the FDG as the most prevalent causes of crop failure in both catchments. The distribution of rainfall in Upper Zigi is bi-modal peaking between March and May with another peak between September and December. In Lower Mngeta catchment, it is unimodal with the rainy seasonpeaking between November and April then it subsiding from May onwards. Flooding in Lower Mngeta catchment usually occurs between March and April, and sometimes in early January and late May [29]. Unlike Upper Zigi sub-catchment, Lower Mngeta catchment is low lying hence prone to flooding which is associated with destruction of properties, including crops. Participants from both sub-catchments noticed that from the 1990s to date the frequency and severity of erratic rainfall has increased. Late rain was reported in the Lower Mngeta catchment from 1997 to 2017, with heavy downpours which have caused the destruction of crops (Figure 3). The findings confirm what other researchers found [30] [31] [32] [33]. One respondent from Mofu Village in Lower Mngeta catchment was recorded saying, "Mofu means the wetland/swamp area in Ndamba language, but now the name has no meaning because of frequent drought. We used to farm throughout the year; nowadays we cannot do that because of unpredictable rainfall, and the soil is dry."

\subsection{Mitigation and Coping Strategy for Agro-Ecosystem Dynamics}

Crop failure has occurred in the study area even for the pre-colonial times. With the advent of new farming practices that colonisation brought about, the coping and adaptation strategies changed (Table 2). Synthesise both ex-ante and post-ante coping strategies. The questionnaire survey revealed some of the communities' coping strategies. These include crop diversification, crop rotation, mixed farming, and keeping of livestock to compliment harvest from the fields. Livestock that is reared include pigs, goats, sheep, cows, and fowls like chicken, geese, and quails. Excreta from these livestock is used as organic fertiliser. In Lower Mngeta catchment, every household cultivate rice, maize and 
Table 2. The coping strategy for crop failure (\%).

\begin{tabular}{|c|c|c|c|c|c|c|}
\hline Strategy & Upper Zigi & Lower Mngeta & $\begin{array}{c}\text { Past } \\
\text { Lower Mngeta }\end{array}$ & $\begin{array}{c}\text { Present } \\
\text { Lower Mngeta }\end{array}$ & $\begin{array}{c}\text { Past } \\
\text { Upper Zigi }\end{array}$ & $\begin{array}{l}\text { Present } \\
\text { Upper Zigi }\end{array}$ \\
\hline Crop diversification & 76.4 & 79.8 & $\sqrt{ }$ & $\sqrt{ }$ & $\sqrt{ }$ & $\sqrt{ }$ \\
\hline Combining farming and livestock & 64.9 & 81.6 & $\sqrt{ }$ & $\sqrt{ }$ & $\sqrt{ }$ & $\sqrt{ }$ \\
\hline Use of improved crop variety & 52.8 & 39.9 & - & $\sqrt{ }$ & - & $\sqrt{ }$ \\
\hline soil and water conservation measures & 46.9 & 55.5 & - & $\sqrt{ }$ & - & $\sqrt{ }$ \\
\hline Use of agro-chemicals & 23.1 & 71.8 & - & $\sqrt{ }$ & - & $\sqrt{ }$ \\
\hline Use of manure & 64.2 & 8.6 & $\sqrt{ }$ & $\sqrt{ }$ & $\sqrt{ }$ & $\sqrt{ }$ \\
\hline Shifting cultivation & 43.3 & 40.8 & $\sqrt{ }$ & & & $\sqrt{ }$ \\
\hline Non Timber forest products & 55.2 & 40.8 & $\sqrt{ }$ & $\sqrt{ }$ & $\sqrt{ }$ & $\sqrt{ }$ \\
\hline Buying food & 50.8 & 60.9 & $\sqrt{ }$ & $\sqrt{ }$ & $\sqrt{ }$ & $\sqrt{ }$ \\
\hline Fishing & - & 18.8 & $\sqrt{ }$ & $\sqrt{ }$ & - & - \\
\hline Cultivation of seasonal crops & - & 11.7 & $\sqrt{ }$ & $\sqrt{ }$ & - & - \\
\hline Irrigation & 22 & 40.8 & - & $\sqrt{ }$ & - & $\sqrt{ }$ \\
\hline Changing of the planting seasons & - & 56.2 & - & $\sqrt{ }$ & - & - \\
\hline Skipping meal & 34.8 & 41.1 & - & $\sqrt{ }$ & - & - \\
\hline Re-sowing & 40 & 21.1 & $\sqrt{ }$ & $\sqrt{ }$ & $\sqrt{ }$ & $\sqrt{ }$ \\
\hline Work parties & - & 15.4 & $\sqrt{ }$ & $\sqrt{ }$ & - & - \\
\hline Forecasting using bio-indicator & 22.3 & 21.1 & - & - & $\sqrt{ }$ & - \\
\hline $\begin{array}{l}\text { Consume animals which are not consumed at } \\
\text { normal circumstance }\end{array}$ & - & 23.5 & $\sqrt{ }$ & $\sqrt{ }$ & - & - \\
\hline Receiving aid & 12.5 & 18.6 & $\sqrt{ }$ & $\sqrt{ }$ & $\sqrt{ }$ & $\sqrt{ }$ \\
\hline Providing grazing areas for livestock & - & 12.5 & - & $\sqrt{ }$ & - & - \\
\hline Staying at farms to guard crops & 29 & 34.4 & $\sqrt{ }$ & $\sqrt{ }$ & $\sqrt{ }$ & $\sqrt{ }$ \\
\hline Rituals and sacrifices & 12.5 & 21.1 & $\sqrt{ }$ & $\sqrt{ }$ & $\sqrt{ }$ & $\sqrt{ }$ \\
\hline Barter trade & 8.1 & 5.6 & $\sqrt{ }$ & $\sqrt{ }$ & $\sqrt{ }$ & $\sqrt{ }$ \\
\hline
\end{tabular}

Note: $(\sqrt{ })$ means present and $(-)$ means absent.

tuber and root crops such as sweet potatoes, cassava and yams, while in Upper Zigi catchment, most of households cultivate maize and cassava. Crop diversification [34] and combining farming and livestock [35] is the best way to deal with food insecurity in Tanzania particularly to small farmers because it is cost effective, ecologically feasible and it's a rational way of reducing uncertainties. The studies by [36] and [37] reported that crop diversification is important way of dealing with risk and vulnerability and also improvement of soil fertility, control weed, pest and diseases as a results it helps to bring the yield and nutrition stability.

There were some common coping strategies in both catchments. These include adoption of soil and water conservation practices, use of improved crop varieties, and application of agricultural chemicals. To reduce soil erosion which 
has been exacerbated by the extreme weather condition like torrential rainfall, Upper Zigi communities practice terrace farming due to the aspect while in Lower Mngeta communities plough ridges; which reduce the speed of water surface runoff, facilitate the water infiltration and attenuate flooding. These practices are not novel in Tanzania as they have been reported to be practiced in another district [31]. Furthermore, improved short-season varieties with high yields were also adopted as coping strategies.

The adoption of new rice was without success in Lower Mngeta catchment as the communities complained the varieties had a foreign taste. Like the rice, new maize varieties were not accepted as they had has less weight per unit volume compared to the native varieties. Compared to local maize varieties, it was reported that management of improved crop varieties is expensive than the local ones due to the need for agro-chemicals. Moreover, communities of Lower Mngeta catchment said the improved varieties putrefy so fast when they are affected by water and it is vulnerable to weevils (dumuzi). This justify that despite some farmers decided to adopt improved crop varieties but still there are some limitations that hinder them to adopt. This calls for integrated research between Plant breeders and social researchers to explore and address issues that hinders the communities to adopt the strategies.

The communities in Lower Mngeta catchment reported to use more agricultural chemicals particularly herbicides for controlling weeds and fertilizers in rice farms than in Upper Zigi catchment. Respondents in Upper Zigi catchment reported to use more manure than the industrial fertilizers. The use of agrochemicals is detrimental to ecosystems due to the harm to non-targeted species, cause of air and water pollution and they also can cause serious health problems [38]. It is true that communities are advised to cope with changes occurring in agricultural sector but also the long impacts of coping strategy should not be forgotten.

Shifting cultivation was reported to be conducted in the study areas when the populations were still low. After some time when it was felt like the soil fertility was deteriorating, other bushes or new forests were cleared leaving few trees. Shifting cultivation allows the land to regenerate the soil quality; reduce soil erosion and easiest way of control weeds. It was reported that; virgin lands have few weeds compared to the land that is being cultivated every year. It was observed that due to scarcity of land due to increase of population and natural resources protection laws with regards to deforestation, only few households practices shifting cultivation. In Lower Mngeta, shifting cultivation particularly is practiced during the flood; some farmers migrate to highland areas where they can farm with less impacts of flooding. In both areas the households in highland practices shifting cultivation. Despite of the shifting cultivation causing an increase of carbon dioxide concentration [20], the results is in agreement with [21] who reported that shifting cultivation in East Malaysia provide an essential contribution to the stability and sustainability of the farming system since it is resilient to exogenous 
disturbances by exhibiting a non-negative trend in crop yielding.

Buying food, fishing activity for Lower Mngeta, eating non-timber forest product such as mushroom, wild rice in Lower Magenta, wild potatoes in Upper Zigi, wild fruits, animals, and wild vegetables were coping strategy which were also used by some of the households in both study areas. Buying food was by use of money or batter trade. Some people work for others and instead of them getting money, they are given food stuffs in return. This system of exchanging labor force and food is more prominent during rainy season when many people do not have food. Doing casual labor during the rainy season has impacts to the inequality of food production; rich will continue to be rich because poor people work for them and automatically the poor have little time to work for themselves. This will continue to bring wealth inequalities among members of the communities which persist over dependence on forest resources such as timber, charcoal and other resources to sustain their life. This leads to increased pressure to the natural resources and in turn impairs environmental conditions. Also, in Lower Mngeta catchment during flooding the availability of fish reported to increase, therefore ensuring people with source of protein and money. [39] Reported that fishing is important coping strategy to rural Cambodia community villages during stresses and shocks.

The Lower Mngeta is the valley and wetland area, after flooding to the end the soil retains water which allows the growing of seasonal crops that does not require much water like maize, sweet potato and cassava. Irrigation was also much practiced in the area especially during the dry seasons. Majority of crops cultivated were horticultural crops such as tomatoes, onions, vegetables, green and hot pepper, egg plants and little maize. The households conducted irrigation by using hand buckets, motorized pumps and hand pumps. This coping strategy of crop irrigation was also found by [7] and [40]. Irrigation plays big role in combating drought [41], although it was reported by [7] and [38] irrigation contributes to further catchment degradation by contributing to increased soil salinity. Use of boat for rice harvesting during much flood is another strategy to cope with crop failure associated with flooding.

Changing of the cropping seasons was reported in Lower Mngeta catchment, before serious change of rainfall pattern, the community used to have two crops in two rainy seasons. The first one is from November to January and the second planting season from March to May. Due to unpredictable rain from November to January, recently people focus in March to May. The results are similar with studies by [34] [40]. This change of plants from two to one may affect food quantity per year. Communities reported to respond the food shortage through skipping meals if other alternatives fail.

With agriculture being the mainstay of livelihoods of the people in the study areas, during the rainy season majority labour on their fields or on other peoples farms in exchange of food and money. This limits them to fully utilize their labour to their own farms leading to persistence low crops production. To cope 
with this shortage of time and labour power, communities have established labour supporting groups; where farmers join together with organized parties to farm to each member of the group. The household on schedule of farming rotation is responsible to prepare local beer and food. When farming is done atone household, they shift to another person. In Tanzania, after labour beer parties were important traditional strategy that fights against food shortage since during the colonial time [35].

Indigenous Knowledge systems play an important role in forecasting weather. Communities have traditional way of predicting farming season. In Lower Mngeta catchment communities predicts rain seasons by listening to frogs sound. Furthermore, in Upper Zigi catchment community uses wild fruits called "Makonde" to forecast rain season. If wild fruits are matured it tells the rainfall is about to start. Apart from wild fruits, appearance of monkey in Zigi catchment between October and January tells that the coming harvesting season will have higher yields. The use of natural resources for season's prediction is also found to Quechua farmers of Bolivia [42] and to the famers of Dodoma, Tanzania [35].

Provision of grazing areas to livestock keepers was practiced in communities of Lower Mngeta catchment by allowing herders to graze their animals in harvested farms. In some cases herders rewarded farmers with animals or paid money to farmers by allowing them to graze, where farmers use the money to buy food. The results are in agreements with [31] as reported famers allow headers to graze in their land as a way to enrich soils by accumulated manure in the farms. The organic matter has capacity to improve soil to absorb water that helps to keep the soils moist even in drought time and reduce soil erosion [43]. In case herds destroy crops, compensation was done with supervision from village government or court.

\section{Conclusion and Recommendation}

The communities in the study areas are experiencing the decrease of agriculture productivity due to changes occurring in the agro-ecosystem. Climate change, advancement of agriculture technology and plantation farming accelerated the changes of agro-ecosystem. The traditional knowledge and cultural values that have been practiced and inherited from their ancestors have been discarded even though they help in restoring agro-ecosystem. The traditional agro-ecosystem practices should be enforced in all areas of study. This will help to avoid the loss of traditional agro-ecosystem knowledge and skills for the coming generations. To cope with dynamics occurring in socio-hydrological systems much emphasis should be put on improving and reviving traditional strategies than only focusing on the modern strategies.

\section{Conflicts of Interest}

The authors declare no conflicts of interest regarding the publication of this paper. 


\section{References}

[1] Conway, G.R. (1986) Agroecosystem Analysis for Research and Development. Winrock International Institute for Agricultural Development, Bangkok, 105 p.

[2] Okey, B.W. (1996) Systems Approaches and Properties, and Agroeco System Health. Journal of Environmental Management, 48, 187-199.

https://doi.org/10.1006/jema.1996.0072

[3] Tilman, D., Balzer, C., Hill, J. and Befort, B.L. (2011) Global Food Demand and the Sustainable Intensification of Agriculture. Proceedings of the National Academy of Sciences of the United States of America, 108, 20260-20264.

https://doi.org/10.1073/pnas.1116437108

[4] FAO, IFAD, UNICEF, WFP and WHO (2018) The State of Food Security and Nutrition in the World 2018. Building Climate Resilience for Food Security and Nutrition. FAO, Rome.

[5] IPCC (2014) Climate Change 2014: Synthesis Report. Contribution of Working Groups I, II and III to the Fifth Assessment Report of the Intergovernmental Panel on Climate Change, $80 \mathrm{p}$.

[6] Wesseling, C., De Joode, B.V.W. and Monge, P. (2001) Pesticide-Related Illness and Injuries among Banana Workers in Costa Rica: A Comparison between 1993 and 1996. International Journal of Occupational and Environmental Health, 7, 90-97. https://doi.org/10.1179/107735201800339506

[7] Lalika, M.C., Meire, P., Ngaga, Y.M. and Chang'a, L. (2015) Understanding Watershed Dynamics and Impacts of Climate Change and Variability in the Pangani River Basin, Tanzania. Ecohydrology \& Hydrobiology, 15, 26-38.

https://doi.org/10.1016/j.ecohyd.2014.11.002

[8] Altieri, M.A. and Nicholls, C.I. (2017) The Adaptation and Mitigation Potential of Traditional Agriculture in a Changing Climate. Climatic Change, 140, 33-45. https://doi.org/10.1007/s10584-013-0909-y

[9] URT (United Republic of Tanzania) (2016) Ministry of Agriculture Livestock and Fisheries: The Tanzanian Fisheries Sector, Challenge and Opportunities. 40 p.

[10] Fuhrer, J. (2003) Agroecosystem Responses to Combinations of Elevated $\mathrm{CO}_{2}$, Ozone, and Global Climate Change. Agriculture, Ecosystems \& Environment, 97, 1-20. https://doi.org/10.1016/S0167-8809(03)00125-7

[11] Altieri, M.A. (2004) Linking Ecologists and Traditional Farmers in the Search for Sustainable Agriculture. Frontiers in Ecology and the Environment, 2, 35-42. https://doi.org/10.1890/1540-9295(2004)002[0035:LEATFI]2.0.CO;2

[12] Kazakova-Mateva, Y. and Radeva-Decheva, D. (2015) The Role of Agroecosystems Diversity towards Sustainability of Agricultural Systems. 147 th EAAE Seminar CAP Impact on Economic Growth and Sustainability of Agriculture and Rural Areas, Sofia, Bulgaria.

[13] Burgess, N., Butynski, T.M., Cordeiro, N.J., Doggart, N.H., Fjeldså, J., Howell, K.M., Kilahama, F.B., Loader, S.P., Lovett, J.C., Mbilinyi, B. and Menegon, M. (2007) The Biological Importance of the Eastern Arc Mountains of Tanzania and Kenya. Biological Conservation, 134, 209-231. https://doi.org/10.1016/j.biocon.2006.08.015

[14] Ricketts, T.H., Dinerstein, E., Boucher, T., et al. (2005) Pinpointing and Preventing Imminent Extinctions. Proceedings of the National Academy of Sciences of the United States of America, 102, 18497-18501. https://doi.org/10.1073/pnas.0509060102

[15] Mombo, F., Speelman, S., Huylenbroeck, G.V., Hella, J. and Pantaleo, M. (2011) 
Ratification of the Ramsar Convention and Sustainable Wetlands Management: Situation Analysis of the Kilombero Valley Wetlands in Tanzania. Journal of Agriculture Extension and Rural Development, 3, 153-164.

[16] URT (2012) National Bureau of Statistics. National Population Census 2003. Dar es Salaam, Tanzania, $264 \mathrm{p}$.

[17] Soviadan, M.K., Koffi-Tessio, E.M., Enete, A.A. and Nweze, N.J. (2019) Impact of Climate Change on Cotton Production: Case of Savannah Region, Northern Togo. Agricultural Sciences, 10, 927-947. https://doi.org/10.4236/as.2019.107071

[18] Shemdoe, R.S. and Abdalah, J.M. (2011) Socio-Economic Baseline Surveys for Selected Coastal Forest Landscapes in Tanzania. Consultancy Report Submitted to WWF Tanzania Country Office, Dar es Salaam, Tanzania.

[19] Resurreccion, B.P. and Elmhirst, R., 2012. Gender, Environment and Natural Resource Management: New Dimensions, New Debates. In: Gender and Natural Resource Management, Routledge, London, 19-36.

[20] Mertz, O. (2009) Trends in Shifting Cultivation and the REDD Mechanism. Current Opinion in Environmental Sustainability, 1, 156-160. https://doi.org/10.1016/j.cosust.2009.10.002

[21] Cramb, R.A. (1993) Shifting Cultivation and Sustainable Agriculture in East Malaysia: A Longitudinal Case Study. Agricultural Systems, 42, 209-226. https://doi.org/10.1016/0308-521X(93)90055-7

[22] Kleinman, P.J., Pimentel, D. and Bryant, R.B. (1995) The Ecological Sustainability of Slash-and-Burn Agriculture. Agriculture, Ecosystems \& Environment, 52, 235-249. https://doi.org/10.1016/0167-8809(94)00531-I

[23] Zidana, A., Kaunda, E., Phiri, A., Khalil-Edriss, A., Matiya, G. and Jamu, D. (2007) Factors Influencing Cultivation of the Lilongwe and Linthipe River Banks in Malawi: A Case Study of Salima District. Journal of Applied Sciences, 7, 3334-3337. https://doi.org/10.3923/jas.2007.3334.3337

[24] Hardlife, Z., Talent, M. and Oswell, R. (2017) Streambank Cultivation along Chiredzi River in Zaka District, Zimbabwe: An Activity Widely Practiced But Institutionally Condemned. International Journal of Agriculture, Environment and Bioresearch, 2, 79-96.

[25] Caillon, S., Cullman, G., Verschuuren, B. and Sterling, E. (2017) Moving beyond the Human-Nature Dichotomy through Biocultural Approaches: Including Ecological Well-Being in Resilience Indicators. Ecology and Society, 22, 27. https://doi.org/10.5751/ES-09746-220427

[26] Biedenweg, K., Harguth, H. and Stiles, K. (2017) The Science and Politics of Human Well-Being: A Case Study in Cocreating Indicators for Puget Sound Restoration. Ecology and Society, 22, 11. https://doi.org/10.5751/ES-09424-220311

[27] Ndiaye, G. and Xu, H. (2016) Impact of Foreign Direct Investment (FDI) on Economic Growth in WAEMU from 1990 to 2012. International Journal of Financial Research, 7, 1-33. https://doi.org/10.5430/ijfr.v7n4p33

[28] Michie, J. (2001) The Impact of Foreign Direct Investment on Human Capital Enhancement in Developing Countries. Report for the Organization for Economic Co-operation and Development (OECD).

[29] URT (2010) Baseline Study of the Kilombero Valley Ramsar Site, Ifakara, Morogoro Tanzania. Department of Zoology and Wildlife Conservation, University of Dar es Salaam, Dar es Salaam, 52 p.

[30] Cooper, P.J.M., Dimes, J., Rao, K.P.C., Shapiro, B., Shiferaw, B. and Twomlow, S. 
(2008) Coping Better with Current Climatic Variability in the Rain-Fed Farming Systems of Sub-Saharan Africa: An Essential First Step in Adapting to Future Climate Change? Agriculture, Ecosystems \& Environment, 126, 24-35. https://doi.org/10.1016/j.agee.2008.01.007

[31] Lema, M.A. and Majule, A.E. (2009) Impacts of Climate Change, Variability and Adaptation Strategies on Agriculture in Semi-Arid Areas of Tanzania: The Case of Manyoni District in Singida Region, Tanzania. African Journal of Environmental Science and Technology, 3, 206-218.

[32] Twomlow, S., Mugabe, F.T., Mwale, M., Delve, R., Nanja, D., Carberry, P. and Howden, M. (2008) Building Adaptive Capacity to Cope with Increasing Vulnerability Due to Climatic Change in Africa-A New Approach. Physics and Chemistry of the Earth, 33, 780-787. https://doi.org/10.1016/j.pce.2008.06.048

[33] Mengistu, D.K. (2011) Farmers' Perception and Knowledge on Climate Change and Their Coping Strategies to the Related Hazards: Case Study from Adiha, Central Tigray, Ethiopia. Agricultural Sciences, 2, 138-145. https://doi.org/10.4236/as.2011.22020

[34] Balama, C., Augustino, S., Eriksen, S. and Makonda, F.B. (2016) Forest Adjacent Households' Voices on Their Perceptions and Adaptation Strategies to Climate Change in Kilombero District, Tanzania. SpringerPlus, 5, 792. https://doi.org/10.1186/s40064-016-2484-y

[35] Schmied, D. (1993) Managing Food Shortages in Central Tanzania. GeoJournal, 30, 153-158. https://doi.org/10.1007/BF00808133

[36] Lin, B.B. (2011) Resilience in Agriculture through Crop Diversification: Adaptive Management for Environmental Change. BioScience, 61, 183-193. https://doi.org/10.1525/bio.2011.61.3.4

[37] Thrupp, L.A. (2000) Linking Agricultural Biodiversity and Food Security: The Valuable Role of Agrobiodiversity for Sustainable Agriculture. International Affairs, 76, 283-297. https://doi.org/10.1111/1468-2346.00133

[38] Aktar, W., Sengupta, D. and Chowdhury, A. (2009) Impact of Pesticides Use in Agriculture: Their Benefits and Hazards. Interdisciplinary Toxicology, 2, 1-12. https://doi.org/10.2478/v10102-009-0001-7

[39] Marschke, M.J. and Berkes, F. (2006) Exploring Strategies That Build Livelihood Resilience: A Case from Cambodia. Ecology and Society, 11, 42. https://doi.org/10.5751/ES-01730-110142

[40] Bele, M.Y., Sonwa, D.J. and Tiani, A.M. (2014) Local Communities' Vulnerability to Climate Change and Adaptation Strategies in Bukavu in DR Congo. The Journal of Environment \& Development, 23, 331-357. https://doi.org/10.1177/1070496514536395

[41] Murendo, C., Keil, A. and Zeller, M. (2011) Drought Impacts and Related Risk Management by Smallholder Farmers in Developing Countries: Evidence from Awash River Basin, Ethiopia. Risk Management, 13, 247-263. https://doi.org/10.1057/rm.2011.17

[42] Boillat, S. and Berkes, F. (2013) Perception and Interpretation of Climate Change among Quechua Farmers of Bolivia: Indigenous Knowledge as a Resource for Adaptive Capacity. Ecology and Society, 18, 21. https://doi.org/10.5751/ES-05894-180421

[43] Bot, A. and Benites, J. (2005) The Importance of Soil Organic Matter: Key to Drought-Resistant Soil and Sustained Food Production (No. 80). Food and Agriculture Organization. 